\title{
A Survey Research on College Students' Satisfaction with Professional Training Plan
}

\author{
Xiuzhen Xie \\ Foreign Languages, Guangzhou College of Technology and Business School, Guangzhou 510800 \\ xiexiuzhen1018@163.com
}

Keywords: College students, trainning plan, satisfaction, survey

\begin{abstract}
The direction of college students 'professional training determines the implementation of some measures for undergraduates, such as resource allocation, teacher force, and talent selection. Moreover, the training plans exert influence on students' future employment, life orientation and social value. By further understanding the college students' satisfaction with the training direction of their majors, the college students will lay a good foundation for their study. In this paper, the author conducted a survey of the present situation of college students' satisfaction with the specialty training in five private colleges in Guangdong Province, using the methods of literature review, questionnaire survey, mathematical statistical analysis and interview, and analyzed the influence of the specialty training satisfaction specialization on students. On this basis, the author puts forward some specific suggestions, which have practical significance to further promote the teaching course of the specialty training satisfaction to be standardized and scientific.
\end{abstract}

\section{Introduction}

Under the background of the increasing contribution of intellectual capital to the economy and the rising enthusiasm of innovation and entrepreneurship, it is particularly urgent to optimize the mode and means of university education. Meanwhile, the professional training plans developed by the university, to a large extent, have impact on or determine the education mode and means. As college students personally experience and benefit from the higher education, taking them as study objects allows researchers to provide direct and effective suggestions for the reform and innovation of college professional training plans. It is vital to do more studies in higher education that focuses on college students' satisfaction towards professional training plans.

Many researchers from China and overseas have conducted in-depth discussions and studies on college students' satisfaction level towards professional training plan, with significant results. The research of scholars can be roughly divided into the following two aspects.

One research filed is about the status quo of college students' satisfaction towards professional training. Chinese scholars Rumei ZHOU, Zongliang SUN (2012), Lixiang WEN (2014), and Haoshu YUE(2015) conducted a sampling survey and found that students' overall satisfaction with professional training plans was not high ${ }^{[1]}$; Larysa Movchan, Inna Zarishniak (2017) indicated that from the perspective of the professional development of economics, modern European education was developed on the principles of democratization and humanization. Democratization means that all participants in the education process are involved in the process of content forming ${ }^{[5]}$

The second aspect is how to improve college students' satisfaction towards professional training plans. Bo LI (2009) proposed that the key is to further clarify the training objectives and specifications, construct a scientific curriculum system, rationally allocate credits and school hours, and increase practical training ${ }^{[4]}$. Similarly, Jie DUAN, Xiangyang SUN, Weiguo CAO, and Kejuan XUE (2015) put forward some suggestions to effectively enhance student's professional knowledge learning. ${ }^{[6]}$

In summary, most Chinese scholars focus on students' satisfaction level in public universities. However, since the establishment of China's higher education, private education resources have been a powerful complement to higher education. The rapid development of private colleges has also brought about a series of problems. At present, the scholars' research on the talent training plans of China's 
private colleges is not deep enough, and the existing studies are mostly discussed from the perspective of school management. Therefore, this paper attempts to take private colleges as the research object, and invites college students as survey respondents, so as to study the college students' satisfaction level towards professional training plans and factors that affect the satisfaction.

\section{Research Design}

\subsection{Sample resource}

400 questionnaires were issued to students in five private colleges in Guangdong Province, China through the Internet. 380 questionnaires were collected, of which 350 were valid, and the effective rate was $87.5 \%$.

\subsection{Sample characteristics}

Of the respondents, 150 (42.9\%) were male, 200 (57.1\%) were female. 75 (21.4\%) were freshmen, 90 (25.7\%) were sophomores; 115 (32.8\%) were juniors and 70 (20\%) were seniors. In the question of census registration, 193 (55\%) came from cities and 157 (45\%) were from rural areas. In the question of major types, 209 (60\%) were students of liberal arts and 141 (40\%) were students of science.

\section{Empirical Analysis}

Excel and SPSS were used to analyze the collected data and the results are as follows.

\subsection{Current situation of college students' satisfaction level towards professional training plan}

3.1.1 College students' understanding level of professional training plan

According to Fig.1, 52\% of the respondents had a low level of understanding of their training plans, and $17 \%$ students had no understanding, which affects their satisfaction level

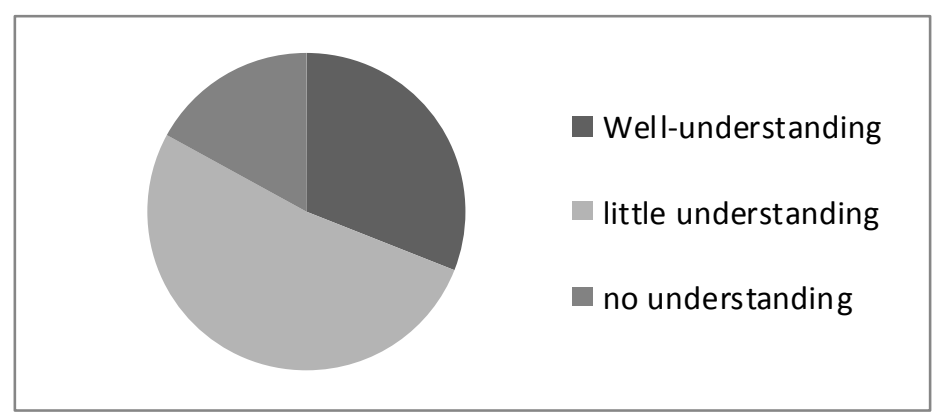

Fig.1 College students' understanding level of professional training plan

Table 1 Differences between professional training plans and college students' expectation

\begin{tabular}{|l|l|l|l|l|}
\hline Difference & Huge & Big & Small & No \\
\hline Numbers & 30 & 75 & 155 & 90 \\
\hline Ratio & $8.5 \%$ & $21.4 \%$ & $44.2 \%$ & $25.7 \%$ \\
\hline
\end{tabular}

According to Table 1, 8.5\% of the respondents thought the plans differ hugely from their expectations. While $69.9 \%$ of them thought there a small or no difference gap, indicating relative high agreement between the plans and students' expectations. Still $21.4 \%$ of the respondents chose relative big differences; representing training plans have to be improved as the need of higher education changes.

Table 2 Relation between professional training plan and students’ major-choosing

\begin{tabular}{|l|l|l|l|l|l|}
\hline & $100 \%$ & $80 \%$ & $50 \%$ & $30 \%$ & 0 \\
\hline Numbers & 265 & 45 & 25 & 15 & 0 \\
\hline Ratio & $75.7 \%$ & $12.8 \%$ & $7.1 \%$ & $0.04 \%$ & $0 \%$ \\
\hline
\end{tabular}


Table 2 shows that $75.5 \%$ of the students thought professional training plans had very important reference significance for major choosing. No students believed there' no links between them, indicating the plans had been a vital reference for choosing their major.

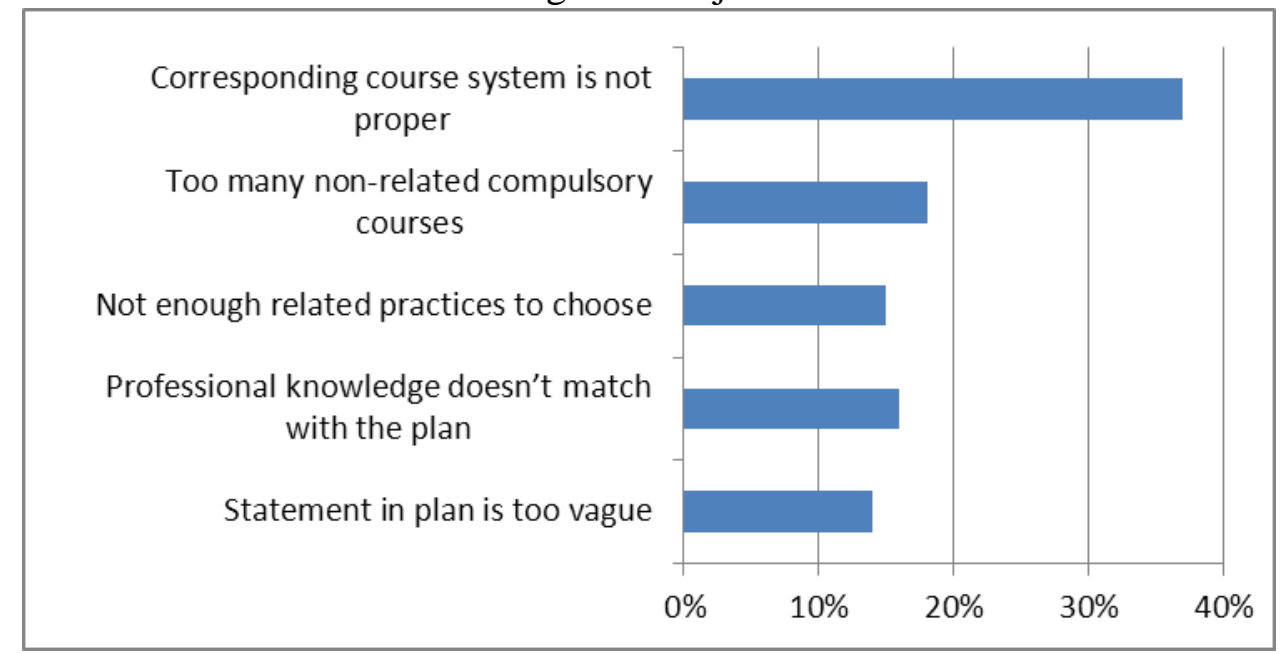

Fig.2 Reasons for dissatisfaction

We found five mains reasons that students are not satisfied with their training plans, listed in Fig.2. "corresponding course system is not proper" shows the highest value (37\%), while other four reasons share a similar value from $14 \%$ to $18 \%$. Therefore, improve the course system will largely increase students' satisfaction level.

3.1.2 Teaching status of major courses in schools

Table 3 Correlation between professional training plans and guidance of specialized courses

\begin{tabular}{|l|l|l|l|l|}
\hline Items & Huge & large & little & no \\
\hline Numbers & 270 & 45 & 25 & 10 \\
\hline ratio & $77.1 \%$ & $12.8 \%$ & $0.07 \%$ & $2.85 \%$ \\
\hline
\end{tabular}

According to Table 3, a large proportion of respondents believed that professional training plans had close relation with guidance of specialized courses (77.1\%), followed by the idea that training plans had some impact on students' learning interest (12.8\%). Through the survey it can be conclude that the satisfaction with professional training plans has connection with students learning interest.

3.1.3 Relation between student career planning courses and professional training plans

Table 4 Correlation between student career planning courses and professional training plans

\begin{tabular}{|l|l|l|l|l|}
\hline Items & Huge & Large & Little & No \\
\hline Numbers & 245 & 65 & 25 & 5 \\
\hline Ratio & $70 \%$ & $18.5 \%$ & $0.71 \%$ & $0.01 \%$ \\
\hline
\end{tabular}

In Table 4, huge correlation shows the largest value (70\%) followed by large correlation (18.5\%). Students lack systematic teaching of career planning, as well as relevant interpretation and guidance of profession, which is the main reason why college students are not satisfied with school's professional training plans.

3.1.4 Students' opinion on reasonability of curriculum design

According to Fig.3, only 31\% of the respondents thought the curriculum design was reasonable; nearly half of them took a neutral position, and still 21\% indicated the curriculum design was unreasonable. The results show satisfaction towards the plan has close relation with curriculum design. The unreasonable design may be attributed to unreasonable or incomplete curriculum reform. 


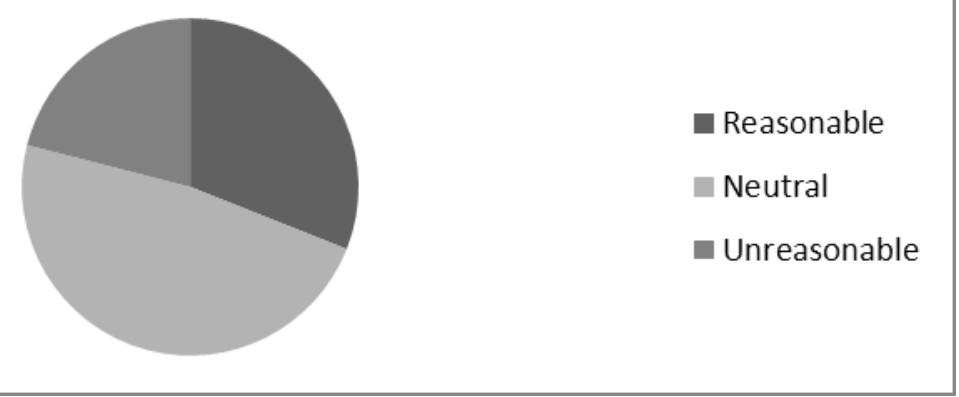

Fig.3 Students' opinion on reasonability of curriculum design

\subsection{Characteristics analysis on college students' satisfaction with professional training plan}

Based on the descriptive statistical method, this paper analyzes the characteristics of college students' satisfaction with professional training plans and the possible factors that affect the satisfaction.

A 5-point Likert-type scale questionnaire was adopted, with (1) strongly disagree, (2) disagree, (3) moderate, (4) agree and (5) strongly agree. B1-B6 refer to public compulsory course, major compulsory course, public elective course, major elective course, entrepreneurship and employment guidance course, and extracurricular scientific and technological activities respectively.

Table 5 Descriptive analysis of college students' satisfaction level towards curriculum design

\begin{tabular}{|l|r|r|r|r|r|}
\hline Items & Average & $\begin{array}{c}\text { Standard } \\
\text { deviation }\end{array}$ & Maximum & Minimum & $\begin{array}{c}\text { Average of the same } \\
\text { kind }\end{array}$ \\
\hline B1 & 3.17 & 1.368 & 5 & 1 & 3.01 \\
\hline B2 & 3.28 & 1.349 & 5 & 1 & 3.18 \\
\hline B3 & 3.68 & 1.201 & 5 & 1 & 3.51 \\
\hline B4 & 3.59 & 1.283 & 5 & 1 & 3.32 \\
\hline B5 & 3.74 & 1.123 & 5 & 1 & 3.67 \\
\hline B6 & 3.48 & 1.294 & 5 & 1 & 3.25 \\
\hline
\end{tabular}

Table 5 shows that the average value of public compulsory course (B3) and entrepreneurship and employment guidance course (B5 are above 3.5, indicating student's high satisfaction level. While other four courses' average values are all below 3.5.

In this paper, the T-test and single factor analysis of two independent samples are used to test whether the difference between gender, grade, census registration, major types and satisfaction towards professional training plan is significant. Take 0.05 as the standard level of significance.

3.2.1 Gender analysis

The difference analysis was carried out by means of independent sample T-test. The results are shown in the following table.

Table 6 The difference test of the mean difference of factors affecting the satisfaction with professional training plans by different genders( $\mathrm{M} \pm \mathrm{SD})$

\begin{tabular}{|c|c|c|c|c|c|}
\hline & $\begin{array}{c}\text { Understanding } \\
\text { of plans }\end{array}$ & Training method & Career guidance & $\begin{array}{c}\text { Curriculum } \\
\text { design }\end{array}$ & Total \\
\hline Male & $0.26 \pm 0.02$ & $0.16 \pm 0.03$ & $0.18 \pm 0.02$ & $-0.24 \pm 0.02$ & $0.14 \pm 0.04$ \\
\hline Female & $0.24 \pm 0.02$ & $0.14 \pm 0.02$ & $0.13 \pm 0.02$ & $-0.23 \pm 0.02$ & $0.12 \pm 0.02$ \\
\hline $\mathrm{t}$ & -0.07 & -0.85 & -1.17 & -0.68 & -1.25 \\
\hline
\end{tabular}

Through T-test, we found male students' values are a little bit higher than those of females, but with no significant differences. $(\mathrm{t}=-1.25, \mathrm{p}=0.81>0.05)$. Except the Curriculum design value, the values of understanding of plans, training method and career guidance in males are higher than those in females.

3.2.2 Grade analysis

Single factor analysis of variance was used to analyze how grades affect satisfaction with professional training plans. 
Table 7 The difference test of the average of satisfaction factors affecting professional training plans in different grades $(\mathrm{M} \pm \mathrm{SD})$

\begin{tabular}{|c|c|c|c|c|c|}
\hline & $\begin{array}{c}\text { Understanding of } \\
\text { plans }\end{array}$ & Training method & Career guidance & $\begin{array}{c}\text { Curriculum } \\
\text { design }\end{array}$ & Total \\
\hline Freshman & $0.28 \pm 0.04$ & $0.18 \pm 0.04$ & $0.18 \pm 0.03$ & $-0.05 \pm 0.06$ & $0.16 \pm 0.02$ \\
\hline Sophomore & $0.24 \pm 0.04$ & $0.16 \pm 0.04$ & $0.17 \pm 0.03$ & $-0.08 \pm 0.06$ & $0.14 \pm 0.02$ \\
\hline Junior & $0.25 \pm 0.02$ & $0.15 \pm 0.03$ & $0.14 \pm 0.02$ & $-0.08 \pm 0.05$ & $0.14 \pm 0.01$ \\
\hline Senior & $0.24 \pm 0.02$ & $0.15 \pm 0.03$ & $0.12 \pm 0.02$ & $-0.08 \pm 0.05$ & $0.14 \pm 0.01$ \\
\hline f & -0.07 & -0.85 & -1.17 & -0.68 & 1.25 \\
\hline
\end{tabular}

According Table 7, the satisfaction level decreases gradually as the grade increases, which means the freshmen are most satisfied with the plan and students of other grades are less satisfied, but the differences are not significant $(\mathrm{f}=1.25, \mathrm{p}=0.34>0.05$ ). The result indicates that with the deepening of the study, students obtain a well understanding of professional training and thus have a higher requirement for the plan.

3.2.3 Census registration analysis

Through the independent sample T-test, we found that students from rural places are more satisfied with those from cities, with no significant differences $(\mathrm{t}=0.08, \mathrm{p}=0.85>0.05)$. The values of training method and career guidance in city students are higher than those of students in rural areas, but the differences are not significant $(\mathrm{t}=0.73, \mathrm{p}=0.82>0.5, \mathrm{t}=0.62, \mathrm{p}=0.6>0.5)$.

3.2.4 Major types analysis

Students of liberal arts have a higher satisfaction level than those of science, but the difference is not significant $(\mathrm{t}=-6.15, \mathrm{p}=<0.05)$. The values of "the understanding level of training plan", "training method" and "curriculum design" in liberal arts students are higher than that in students of science ( $\mathrm{t}=-$ 5.45, $\mathrm{p}<0.05>0.5, \mathrm{t}=0.612, \mathrm{p}=<0.5)$.

\section{Conclusion}

Through the above statistical analysis, the following conclusions can be drawn.

\subsection{Student level}

From the aspect of students: Students' understanding of professional training plans is not high, which may be attributed to students' lack of subjective initiative and the lack of interpretation of corresponding professional training plans. The professional training plan is an important reference for college students to choose their major. Thus, plans' reasonability and standardability affect students' major choosing with a probability of $80 \%$. If students do not receive sufficient guidance and detailed interpretation of professional curriculum training plans from school, they will become dissatisfied with training plans.

\subsection{School level}

From the school level, factors that affect college students' satisfaction level towards professional training plan are the follows. Firstly, nearly $90 \%$ of the students thought that the major guidance courses have relationship with the satisfaction with the training programs. The second vital factor is students' career planning course. Nearly $90 \%$ of the students believed that a clear career planning provides students with confidence and direction for future development. The third one is the reasonability of curriculum design. Statistics showed that the satisfaction levels of public compulsory courses, major compulsory courses, major elective courses, and extracurricular science and technology activities were lower than those of public elective courses and entrepreneurship and employment guidance course. The last factor is the imperfections in professional training plans including incomplete course and knowledge system, and too many compulsory courses that are not closely related to the training direction. 


\subsection{Sample characteristics}

From the basic characteristics of the sample, male students believed that the degree of understanding of professional training plans, professional curriculum training methods and career planning guidance were the main factors affecting plan satisfaction, while female students thought that the reasonability of curriculum design was the main force affecting the satisfaction. We found a negative correlation between satisfaction level and grade. The overall satisfaction levels towards professional training plan of liberal arts students and science students were different. Students enrolled in science majors were less satisfied, which is mostly likely due to insufficient equipment and outstanding teachers. The funds for running private colleges are limited, as they are basically provided by the investors themselves. At the same time, the platform of private colleges is not attractive enough to excellent teachers. There were also some differences in the understanding of the training plan, the major curriculum training method, the major curriculum structure design, and career planning guidance.

\section{Suggestions}

Through the survey and analysis, we found that the college students' satisfaction levels towards professional training plans affect their self-directed learning, and further impact their performance in study, and even employment. To improve the satisfaction level, this paper proposed the following suggestions.

\subsection{Enhance students' understanding of professional training plans}

From the perspective of the students themselves, they should read more major-related books and studies of their fields, actively participate in various professional practice activities, from which students can find pleasure of major learning, identification, and satisfaction with training plans. From the perspective of the school, general education courses are welcomed in the first-year of university. After one year's learning, when students gained more experience, give students a second change to re-select their majors. Moreover, necessary interpretation of majors and professional training programs shall be provided to students as soon as they enter the college, so as to help them have a comprehensive and indepth understanding of the professional training objectives, curriculum system, learning methods, and key courses before formal study, making the students' expectations more consistent with the professional training plan.

\subsection{Promote structural reform of professional training plans in higher education}

Structural reform of professional training plans in higher education can be carried out from the following three aspects.

Lift restrictions of changing majors. Set up a major changing exam for to facilitate students to choose a major they are interested in. This not only reduces the difficulty of changing majors, but also gives some guidance to students' professional choices, and the satisfaction level will consequently be improved.

Secondly, optimize the professional training plans. According to the results of the sample survey and analysis, improving compulsory courses is school's first priority. Factors including an imperfect curriculum and professional knowledge system, compulsory courses that do not match the training plan or vague statements in the plans, all lead to students' low recognition of the professional training programs as well as low satisfaction level. For example, in order to embody the characteristics of English teaching, a large number of credits for English-related courses have been added to the public compulsory courses, which make it impossible to schedule some compulsory courses and makes it difficult to perfect the professional curriculum system. Besides compulsory courses, properly adding career planning courses can improve students' recognition of professional training programs.

Thirdly, optimize teaching syllabus. The syllabus is the guiding document for subject teaching and the basis for the curriculum design structure. The syllabus is not only a lecture outline, but also an outline for guiding students to self-study and develops their abilities. Whether the curriculum design structure is reasonable or not is the main factor that affects the satisfaction of the program. The survey shows that college students are less satisfied with the curriculum design of public compulsory courses, major 
compulsory courses, major elective courses and extracurricular science and technology activities. Therefore, efforts should be made to focus on the design of the syllabus for these four types of courses.

\subsection{Find and solve students' learning burnout problem in time}

With the extension of college students' school time, their satisfaction with professional training plans is decreasing. This phenomenon is more of a psychological learning burnout problem, which will reduce students' enthusiasm for learning. Schools should pay attention to the mental health development of students, set up a special psychological counseling room, and establish a sound mental health maintenance system.

\section{References}

[1]. Zhou Rumei, \& Sun Zongliang. "Satisfaction study on the training program of International trade professionals in independent colleges-- taking the City Science and Technology College of Chongqing University as an example.” Education Teaching Forum[J]. 2012 (35) (in Chinese)

[2]. Wen Lixiang. A status study on the students' satisfaction of applied psychology professional training — take N University as example[D]. Nanchang University.2014. (in Chinese)

[3]. Yue Haoshu. A Status Study on Students' Satisfaction of the Cultivation Work for Dual-academic Degree of Undergraduate-Taken N University as Example[D]. 2015. (in Chinese)

[4]. Li Bo. Optimize professional training program to improve the education satisfaction of adult students[J]. Career Horizon.2009(3) (in Chinese)

[5]. Larysa Movchan, Inna Zarishniak. The Role of Elective Courses in Students' Professional Development: Foreign Experience[J], 2017

[6]. Jie DUAN, Xiangyang SUN, Weiguo CAO, Kejuan XUE. Methods to Improve the Teaching Effect of the Professional Course of the University.2015 